conducting matter is moving in the static magnetic field. A detailed study of the effect of finite conductiv. ity on the different modes will be published elsewhere.

These waves may be of interest in solar physics, and lead to an estimate of the relative importance of the processes suggested by Schwarzschild ${ }^{6}$ and by Alfvén ${ }^{3}$ for heating the solar atmosphere.

I am indebted to Prof. H. Alfvén for stimulating discussions. This investigation has been supported by the Knut and Alice Wallenberg Foundation.

Department of Electronics, N. Herlofson

Royal Institute of Technology, Stockholm 26.

March 23.

1 Alfvén, H., "Cosmical Electrodynamics", chap. 4 (Oxford, 1950).

8 Walén, C., Ark. f. mat., astr. o. fysik, 30 A, No. 15 (1944). Lundquist S., Phys. Rev., 76, 1805 (1949).

sAlfvén, H., "Cosmical Electrodynamics", 151 (Oxford, 1950).

- Richtmyer, R. D., and Teller, E., Phys. Rev., 75, 1729 (1949). Fermi E.. Phys. Rev., 75, 1169 (1949). Alfvén, H., Phys. Rev., 75, 1732 (1949); ibid., 277,375 (1950).

- Åström, E. (see preceding communication).

- Schwarzschild, M., Astrophys. J., 104. 203 (1948).

\section{The Karyolytic Factor in the Serum of Rats Injected with Colchicine}

Recentuy, Euler et al. ${ }^{1,2}$ have described $\dot{a}$ peculiar effect of certain normal, as well as sarcomatous, rat sera on the stainability of tumour cells. When smear preparations of mouse ascites carcinoma or rat Jensen sarcoma were incubated with the sera, a distinct loosening of the internal structure of the nuclei, demonstrated by May-Grünwald and Giemsa stains, and a total loss of Feulgen nucleal reaction, were observed. This effect was termed the 'karyolytic effect'. It was also noticed when smear preparations of rat liver pulp were incubated with some samples of normal and sarcomatous rat sera. Human and rabbit blood serum, however, did not show the effect. No relationship appeared to exist between the effect observed in the case of certain rat sera and any known physiological, pathological or dietetic factors. Recent attempts ${ }^{3}$ to provoke 'karyolysis' by active immunization have not yet yielded any distinct positive results.

With the view of studying further the nature of the karyolytic factor, a method was sought of reproducing the effect by other means. The action

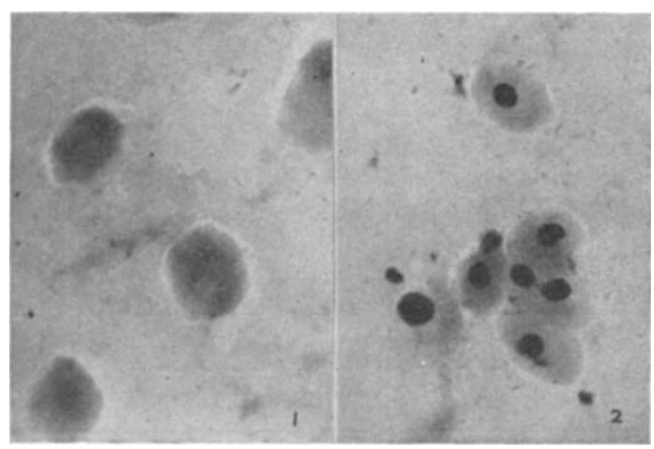

Fig. 1. Photomicrograph of rat-liver smear preparation treated with serum from the blood of rats injected with colchicine,
showing distinct loss of stainability by Feulgen nucleal stain. $(\times 500)$

Fig. 2. Photomicrograph of rat-liver smear preparation without serum treatment (control), showing the presence of intact nuclei.
$(\times \mathbf{5 0 0})$ of certain mitotic poisons on the karyolytic effect of rat serum was therefore examined. Very interesting and consistent results were obtained in the case of colchicine. Colchicine in doses of $100-600 \mu \mathrm{gm}$. were injected into rats weighing $150-300 \mathrm{gm}$., and the karyolytic effect of serum obtained from the blood collected after various intervals of time from injection was determined as before ${ }^{1,2}$. The smear preparations of liver were fixed with methanol, incubated with serum at $37^{\circ} \mathrm{C}$. for $16-20 \mathrm{hr}$. and stained with Feulgen reagent.

There is a distinct loss of stainability by Feulgen nucleal stain when sera of rats injected with colchicine were incubated with smear preparations of liver obtained from the same rat (Fig. 1). The effect is more pronounced in the case of sera of blood collected twenty-four hours after the injection of colchicine, the effect increasing with increase in the concentration of colchicine injected. At lower concentrations of colchicine the nucleus stains very faintly after treatment with serum. In all these cases the cytoplasm is, however, much the same in control and serumtreated preparations. Complete removal of Feulgenpositive materials from the nuclei in smear preparations treated with serum of colchicine-injected rats was invariably observed when serum was obtained from the blood of rats sacrificed twenty-four hours after the injection of colchicine. The karyolytic effect of serum of colchicine-injected rats was also observed when liver preparations from normal rats (without colchicine injection) were used. The effect is therefore specific to serum.

Injection of acridine did not show such distinct and total loss of nucleal stain of practically all the cells coming in contact with the serum, as was observed in the case of colchicine. There was, however, a very small percentage of cells in which the nucleal stain was very weak. Injection of urethane and the sodium salt of camphoric acid did not show any such effect.

The enzymic nature of the karyolytic factor, its possible identity with some of the known enzyme systems present in serum and its physiological role are being investigated. Full details of the above investigation will be published elsewhere.

I wish to thank Prof. Hans von Euler for providing facilities for carrying out these investigations.

Note added in proof. Shortly after submitting this letter, it was found that the karyolytic factor occurs in the serum of normal guinea pigs.

Vitamin Institute and

K. V. GIRI

Institute for Research in Organic Chemistry, University of Stockholm. Feb. 20.

1 v. Euler, H., Heller, L., and Curman, C., Arkiv for Kemi, 1, 299
(1949).
v. Euler, H., Heller, L., and Curman, C., Arkiv for Kemi, 1, 373
(1949).
s. Euler, H., and Heller, L., Arkiv for Kemi, 1, 425 (1949),

\section{c-Mitotic Action of some Simple Gases}

Levan and Östergren ${ }^{1}$, and Gavaudan ${ }^{2}$ have stressed the fact that the phenomena of mito-inhibition and of c-mitosis can be induced by, inter alia, a range of substances of diverse chemical constitution, alike only in this, that they belong to the class of inert narcotics. The first-named investigators observed a correlation between the threshold molar concentra. tions of such 'c-mitotic' substances and their water 